\title{
Research on the Application of Positive Discipline for 3-6-year-old Learners in English Learning Classroom
}

\author{
Huanhuan Ren ${ }^{1,}$, Chi Ma ${ }^{2, b}$ \\ ${ }^{1}$ Teaching and Research Institute of Foreign Languages, Bohai University, Jinzhou, 121013, China \\ ${ }^{2}$ Jinzhou Institute of Forestry Research, Jinzhou Forestry Bureau, Jinzhou, 121013, China \\ arenhuanhuan2014@163.com, ${ }^{\mathrm{b}}$ machi2014 @tom.com
}

Keywords: MOOC; Reform; English Language Teaching; China

\begin{abstract}
There's no question that positive discipline has made institutions consider the future of children education in classroom, and many instructors have employed the proven effective strategies of positive discipline among young children. The truth is that positive discipline is supported by theory of positive behavior support and has sprang into limelight in children education with its criteria. It's suggested that the application of positive discipline for 3-6-year-old learners within EFL classroom be considered and conducted with focus on three main things or areas of English enlightenment, i.e. recognizing needs and inspiring intrinsic motivation, respecting learners and redirecting negative behaviors and preventive measures for language learners, so as to create a classroom climate that maximizes academic learning in English enlightenment. It's hoped that this thesis provides a useful reference for English enlightenment practice among young students.
\end{abstract}

\section{Introduction}

Over the years millions of parents have employed the amazingly effective strategies of positive discipline to raise happy, well-behaved, and successful children. It's found that instructors who are moving toward positive discipline often feel the impact of it. Then how to create a classroom climate that enhances academic learning? In which way should people apply positive discipline for 3-6-year-old learners in English learning classroom? The purpose of this thesis is to find out practical strategies to conduct English language enlightenment in classroom with an eye on the implications of the book series of positive discipline, the ideas behind positive discipline, and criteria analysis of positive discipline, so as to cultivate a child who is motivated and well-behaved within the process of language enlightenment in classroom. This paper is a summary of this research work, which hopefully provides a useful reference for English enlightenment practice among young students.

\section{The Introduction and Advantages of Positive Discipline}

The Book Series of Positive Discipline. Based on the best selling Positive Discipline books by Dr. Jane Nelsen, Lynn Lott, Cheryl Erwin, Kate Ortolano, Mary Hughes, Mike Brock, Lisa Larson and others, Positive discipline teaches important social and life skills in a manner that is deeply respectful and encouraging for both children and adults (including parents, teachers, childcare providers, youth workers, and others)[1]. There are many books devoted in positive disciplines. For twenty-five years, the book of Positive Discipline is regarded as the classic guide to helping children develop self-discipline, responsibility, cooperation, and problem-solving skills, and the gold standard reference for grown-ups working with children[2]. Some of other five books include Positive Discipline: The First Three Years, Positive Discipline for Preschoolers, Positive Discipline for Teenagers, Positive Discipline in the Classroom, Positive Discipline A-Z, Positive Discipline Parenting Tools, aimed at respectively different areas of positive discipline, i.e., laying the foundation for raising a capable, confident child from infant to toddler; raising children who are responsible, respectful, and resourceful for their early years; empowering your teens and yourself through kind and firm parenting developing mutual respect, cooperation, and responsibility in 
classroom; 1001 solutions to everyday parenting problems; the 49 most effective methods to stop power struggles, build communication, and raise empowered, capable kids[3-8].

The Ideas Behind Positive Discipline. Positive discipline is a discipline model used by schools, and in parenting, focusing on the positive points of behavior, based on the idea that there are no bad children, just good and bad behaviors[9]. It's suggested that people teach and reinforce the good behaviors while weaning the bad behaviors without hurting the child verbally or physically[10]. Most notably, one can obtain insights into this parenting and educational philosophy through tapping and delving into the name of the term. It's argued that the word discipline means teach or guide, and it doesn't mean punish or control[11]. Contrasting with negative discipline which may involve angry, destructive, or violent responses to inappropriate behavior, positive discipline uses the full range of reinforcement and punishment options (including positive reinforcement, negative reinforcement, positive punishment, and negative punishment) in a kind, encouraging, and firm manner[12]. Nelsen coaches parents and teachers to be both firm and kind, so that any child-from a three-year-old toddler to a rebellious teenager-can learn creative cooperation and self-discipline with no loss of dignity[13]. Also the kind and firm parenting style, advocated by positive discipline, is with an eye on a long-term parenting as opposed to short-term parenting[14]. Simply stated, the key to positive discipline is not punishment, but mutual respect, with the aim of teaching young people to become responsible, respectful and resourceful members of their communities.

Benefits of Positive Discipline Program. Millions of children have already benefited from the counsel in this wise and warmhearted parenting style. Specifically benefits of positive discipline program can be denoted in three dimensions. Firstly, positive discipline gives children the tools they need for a well-adjusted life with this proven treasure trove of practical advice. People engaging in positive discipline are not ignoring problems. Rather, they are actively involved in helping their children learn how to handle situations more appropriately while remaining calm, friendly and respectful to the children themselves[15]. Besides, better student-teacher relations can be established through going for positive discipline program. Instructors can enrich the relationship with their children through focusing on solutions while being kind and firm. Rather than doling out arbitrary punishments when their children fall short of those expectations, instructors hold high expectations and give appropriate consequences or allow learners to occur naturally. Students recognize desirable positive behaviors, rather than feel attacked. Positive discipline is aimed at developing mutually respectful relationships. Lastly, efforts are being made to prevent occurrences such as dropping out of school. Statistics show that each year, close to one third of eighteen-year-olds do not finish high school[16]. This situation is expected to be solved through the use of positive discipline, as the focus of positive discipline is to establish reasonable limits and guide children to take responsibility to stay within these limits, or learn how to remedy the situation when they don't.

\section{Criteria Analysis of Effective Positive Discipline for 3-6-year-old Learners in EFL Classroom}

Five Criteria for Positive Discipline. How to conduct positive discipline among young learners? Several criteria are summarized by Jane Nelsen in her book, offering a guideline for novices in positive discipline. They include respectful and encouraging; sense of belonging and significance; effective long-term; social and life skills; discovering how capable they are[17]. Then let's look at them closely. Firstly, instructors keep kind and firm at the same time, neither punitive nor permissive. Secondly, children are helped to feel a sense of belonging and significance through connection. Recent research tells us that children are hardwired from birth to connect with others, and that children who feel a sense of connection to their community, family, and school are less likely to misbehave[18]. Thirdly, adults should consider what the children are thinking, feeling, learning, and deciding about themselves and their world - and what to do in the future to survive or to thrive. It's wise to make teaching effective long-term, whereas, punishment works short term, but has negative long-term results. Fourthly, children are taught with valuable social and life skills for good character, such as respect, concern for others, problem-solving, accountability, contribution, cooperation. Lastly, positive disciple invites children to discover how capable they are and to use 
their personal power in constructive ways. All in all, the five aspects of children learning should be given much concern whilst conducting positive discipline among young learners.

Positive Behavior Support. Once the five criteria are identified, much work should be done to apply positive discipline among children learners. Just like the five criteria imply, teachers should limit their instructional endeavors for positive behavior support in this process. Positive discipline has its root in the theory of positive behavior support. Positive behavior support is a form of child discipline that is a proactive and positive approach used by staff, parents and community agencies to promote successful behavior and learning at home and at school for all students[19]. It's argued that there are no bad children, but appropriate and inappropriate behaviors. And people's inappropriate behaviors are difficult to change because they are functional and they serve a purpose for them. It's found that adults in a child's environment will reinforce his or her undesired behaviors because the child will receive objects or attention because of his behavior[20]. That is, inappropriate behaviors are supported by reinforcement in the environment. The job for those who are working on positive discipline is to deliver a supportive and nurturing learning environment for learners to grow and develop without inappropriate behaviors. There are many different behavioral strategies can be used to encourage individuals to change their inappropriate behavior through positive discipline.

\section{The Application of Positive Discipline for 3-6-year-old Learners within English Learning Classroom}

Recognizing Needs and Inspiring Intrinsic Motivation. Instructors should realize the importance of recognizing learner needs and inspiring intrinsic motivation in English enlightenment. On one hand, learners should be understood by instructors in many aspects, one of which is to get hang of why to be engaged into English enlightenment and what is the individual need of each learner. In positive discipline theory, it is posited that when children misbehave they are displaying that a need of theirs is not being met. In dealing with the misbehavior, it's suggested that focusing on the unmet need rather than the behavior itself will have better results[21]. Teachers will enjoy motivated, eager students through encouraging learners to meet their needs and pursue the goal that make them happy. On the other, the motivation behind students' behavior provides a reference for further proactive actions of learners. In the process of English learning at early times of life, children are expected to be cultivated and inspired with intrinsic motivation drawn from internal sources, out of a sense of ethics or a desire to feel good about oneself rather than stems from a desire to avoid punishment or attain a reward like extrinsic motivation[22]. The idea of doing away with both positive and negative reinforcement as much as possible is suggested as a way to inspire intrinsic motivation. This is what positive discipline seeks to work on, so that children learn to act correctly even when there will be no external reward or punishment for behavior[23].

Respecting Learners and Redirecting Negative Behaviors. Teachers are encouraged to use positive discipline to restore order and civility to English learning classrooms and homes through redirecting negative behaviors in a respectful and encouraging way. No matter children show positive behavior or negative behaviors in foreign language learning in classroom, English instruction should be delivered in a kind but firm manner, preserving the trust and mutual respect between the adult and the child. In any case, children are supposed to be respected even if there are moments for instructors filled with anger, frustration, and, at times, desperation. As for the undesired behaviors or challenges, teachers have to take time to recognize and identify the belief behind the behavior, or the reasons kids do what they do. Rather than merely attempting to change behavior, teachers are supposed to work to change those believes. After that, instructors can employ family and class meetings to tackle behavioral challenges with positive discipline. Specifically speaking, in order to encourage positive behaviour to replace misbehavior, it's wise to redirect the child's behavior into something positive and helpful, and to focus on solutions instead of dwelling on the negative behaviors. All in all, instructors should see misbehavior as a chance to teach nonpunitive discipline, so as to turn mistakes into learning opportunities in the process of English enlightenment .

Making Preventive Measures for Language Learners. Positive discipline can be utilized as a 
preventive strategy to avoid undesired learning situations in advance. Then what preventive measures should be taken by instructors in the process of English learning among 3-6-year-old learners? It's argued that truly effective parenting or teaching is about connection before correction. In light of it, full understanding and mutual trust should be established among learners and instructors, in hope that effective communication can occur anytime and anywhere when necessary. In this easy learning climate without excessive control or punishment, instructors are more successful in setting effective boundaries, creating clear and fair rules, and teaching kids the importance of taking charge of their own behaviors, so as to raise well-behaved children without punishment. Furthermore, learners can be invited into advance planning session where both of them are inspired to think about how to respond to difficult situations clearly and directly when they arise, and encouraged to brainstorm the potential problem and its possible solutions. For learners, thinking how to do is more important than thinking what to do in learning challenges, as the former makes the children responsible for themselves. The consequences are that learner misbehaviors can be prevented when children are enabled and willing to learn from mistakes.

\section{Summary}

It can be concluded that instructors who are moving toward positive discipline often feel the impact of it. The truth is that positive discipline is supported by theory of positive behavior support and has sprang into limelight in children education with its criteria. It's suggested that the application of positive discipline for 3-6-year-old learners within EFL classroom be considered and conducted with focus on three main things or areas of English enlightenment, i.e. recognizing needs and inspiring intrinsic motivation, respecting learners and redirecting negative behaviors and preventive measures for language learners, so as to create a classroom climate that maximizes academic learning in English enlightenment. It's hoped that this thesis provides a useful reference for English enlightenment practice among young students.

\section{Acknowledgements}

This work is part of the project of On Cultivating and Developing Liaoning Scientific Foreign Language Talents with View to Bourdieu' Theory, the project of On Establishing Generative Mechanism of EFL Autonomous Learning Behaviors and Strengthening Development of Learning Field in Ubiquitous Learning Space, and the project of On Constructing Mechanism and Strategies for College English Autonomous Learning Abilities via Mobile Multimedia. This research was supported by the fund of Liaoning Planning of Philosophy and Social Science (Project No. L16CYY001), the fund of Liaoning Provincial Federation Social Science Circles (Project No. 2017lslktyb-019), and the fund of the Thirteenth Five-Year Plan of Education Sciences of Liaoning Province (Project No. JG16DB013).

\section{References}

[1] What is Positive Discipline? Retrieved from the information on http: // images. shulcloud. com/ 615/ uploads / Resources / what_is_pd_article-1-10.pdf

[2][17]Jane Nelsen. Positive Discipline, the classic guide to helping children develop self-discipline, responsibility, cooperation, and problem-solving skills. Ballantine Books, 2006.

[3] Jane Nelsen, Cheryl Erwin, Roslyn Duffy. Positive Discipline: The First Three Years, Revised and Updated Edition: From Infant to Toddler--Laying the Foundation for Raising a Capable, Confident Child. Harmony, 2015

[4] Jane Nelsen, Cheryl Erwin , Roslyn Ann Duffy. Positive Discipline for Preschoolers: For Their Early Years--Raising Children Who are Responsible, Respectful, and Resourceful (Positive Discipline Library). Harmony, 2007. 
[5][14] Jane Nelsen, Lynn Lott. Positive Discipline for Teenagers, Revised 3rd Edition: Empowering Your Teens and Yourself Through Kind and Firm Parenting, Harmony, 2012

[6] Jane Nelsen, Lynn Lott, H. Stephen Glenn. Positive Discipline in the Classroom: Developing Mutual Respect, Cooperation, and Responsibility in Your Classroom. Harmony, 2013

[7] Jane Nelsen, Lynn Lott, H. Stephen Glenn. Positive Discipline A-Z: 1001 Solutions to Everyday Parenting Problems (Positive Discipline Library). Harmony, 2007

[8] Jane Nelsen, Lynn Lott, H. Stephen Glenn. Positive Discipline A-Z: 1001 Solutions to Everyday Parenting Problems (Positive Discipline Library). Harmony, 2007.

[9][10][12][13][15]Positive discipline. Retrieved from the information on https://en.wikipedia.org/wiki/Positive_discipline\#Using_Gerunds

[10]Positive Discipline Strategies, Retrieved from the information on https://www.aap.org/en-us/professional-resources/Reaching-Teens/Documents/Private/Positive_dis cipline_handout.pdf

[16] John Bridgeland, John Dilulio, Karen Karen. The Silent Epidemic: Perspectives of High School Dropouts. Washington, D.C: Civic Enterprises, LLC. 2006.

[18] About Positive Discipline, Retrieved from https://www.positivediscipline.com/

[19][20]Positive behavior support, Retrieved from the information on https://en.wikipedia.org/wiki/Positive_behavior_support\#Behavioral_strategies_available

[21] Amy Morin. The Difference Between Punishment and Discipline. Retrieved from About.com, 4 March 2016.

[22] Kendra Cherry. What Is Intrinsic Motivation? Retrieved from About.com, 4 March 2016.

[23]Jump up API. Practice Positive Discipline. Attachment Parenting International, 4 March 2016. 